2. Foo CY, Bonsu KO, Nallamothu BK, Reid CM, Dhippayom T, Reidpath DD, et al. Coronary intervention door-to-balloon time and outcomes in ST-elevation myocardial infarction: a meta-analysis. Heart. 2018;104:1362-9.

3. Kapur NK, Alkhouli MA, DeMartini TJ, Faraz H, George ZH, Goodwin MJ, et al. Unloading the left ventricle before reperfusion in patients with anterior STsegment-elevation myocardial infarction. Circulation. 2019;139:337-46.

4. Guan Z, Guan X, Gu K, Lin X, Lin J, Zhou W, et al. Short-term outcomes of on- vs off-pump coronary artery bypass grafting in patients with left ventricular dysfunction: a systematic review and meta-analysis. J Cardiothorac Surg. 2020;15:84-96.
5. Ouweneel DM, Schotborgh JV, Limpens J, Sjauw KD, Engström AE Lagrand WK, et al. Extracorporeal life support during cardiac arrest and cardiogenic shock: a systematic review and meta-analysis. Intensive Care Med. 2016; 42:1922-34.

6. Saku K, Kakino T, Arimura T, Sunagawa G, Nishikawa T, Sakamoto T, et al. Left ventricular mechanical unloading by total support of Impella in myocardial infarction reduces infarct size, preserves left ventricular function, and prevents subsequent heart failure in dogs. Circ Heart Fail. 2018; 11:e004397.
See Article page 2046.

\section{Commentary: "The weight" will be worth it: Avoiding premature judgment on the success or failure of left ventricular unloading in mitigating reperfusion injury}

\author{
Michael I. Brener, MD, ${ }^{\mathrm{a}}$ and \\ Daniel Burkhoff, MD, PhD ${ }^{\mathrm{a}, \mathrm{b}}$
}

Mortality following acute myocardial infarction (AMI) has declined substantially with the advent of primary reperfusion therapy, but the incidence of new-onset heart failure remains stubbornly high. A long list of therapies and treatment paradigms like ischemic preconditioning and novel pharmacology showed promise in preclinical models but have failed to reduce infarct size in clinical trials. In this issue of the Journal, Goodwin and Selzman ${ }^{1}$ rigorously describe the recent literature surrounding left ventricular (LV) unloading and its innovative application to mitigate reperfusion injury following AMI.

Preclinical models of LV unloading with a transvalvular axial flow pump like the Impella family of devices (Abiomed Inc, Danvers, Mass) have shown compelling

From the a Division of Cardiology, Columbia University Medical Center-NewYork Presbyterian Hospital; and ${ }^{\mathrm{b}}$ Cardiovascular Research Foundation, New York, NY.

Disclosures: Dr Burkhoff reports consulting for IMPULSE Dynamics and institutional grant support from Ancora Medical; Dr Brener reported no conflicts of interest.

The Journal policy requires editors and reviewers to disclose conflicts of interest and to decline handling or reviewing manuscripts for which they may have a conflict of interest. The editors and reviewers of this article have no conflicts of interest.

Received for publication July 27, 2020; revisions received July 27, 2020; accepted for publication Aug 17, 2020; available ahead of print Aug 21, 2020.

Address for reprints: Michael I. Brener, MD, Cardiovascular Medicine, Presbyterian Hospital, 622 West 168th St, Floor 3, Room 347, New York, NY 10032 (E-mail: mib2102@cumc.columbia.edu).

J Thorac Cardiovasc Surg 2021;161:2052-3

$0022-5223 / \$ 36.00$

Copyright (c) 2020 by The American Association for Thoracic Surgery

https://doi.org/10.1016/j.jtcvs.2020.08.041

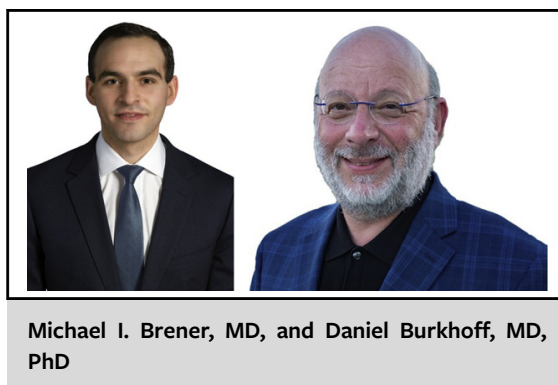

CENTRAL MESSAGE

LV unloading has the potential to

limit injury associated with

myocardial infarction and reper-

fusion therapies. More work re-

mains to translate these benefits

from the bench to the bedside.

results with respect to reperfusion injury. Recently, Esposito and colleagues ${ }^{2}$ demonstrated activation of a cardioprotective cascade led by the signaling protein stromal-derived factor- $1 \alpha$ in a swine model where reperfusion was delayed for at least 30 minutes after unloading with an Impella device. These findings provide a mechanistic explanation for the improved ventricular performance observed in previous large animal studies. Smalling and colleagues ${ }^{3}$ almost 3 decades ago and Meyns and colleagues ${ }^{4}$ almost 2 decades ago showed that an axial flow device significantly reduced ventricular filling pressures and infarct size when applied during ischemia before reperfusion. These improvements correlated with decreases in myocardial oxygen consumption created by unloading. ${ }^{4}$ However, Goodwin and Selzman astutely remind us that ischemic time cannot be controlled as it can in the preclinical setting, and that animal models fail to replicate the mix of comorbidities shared by 


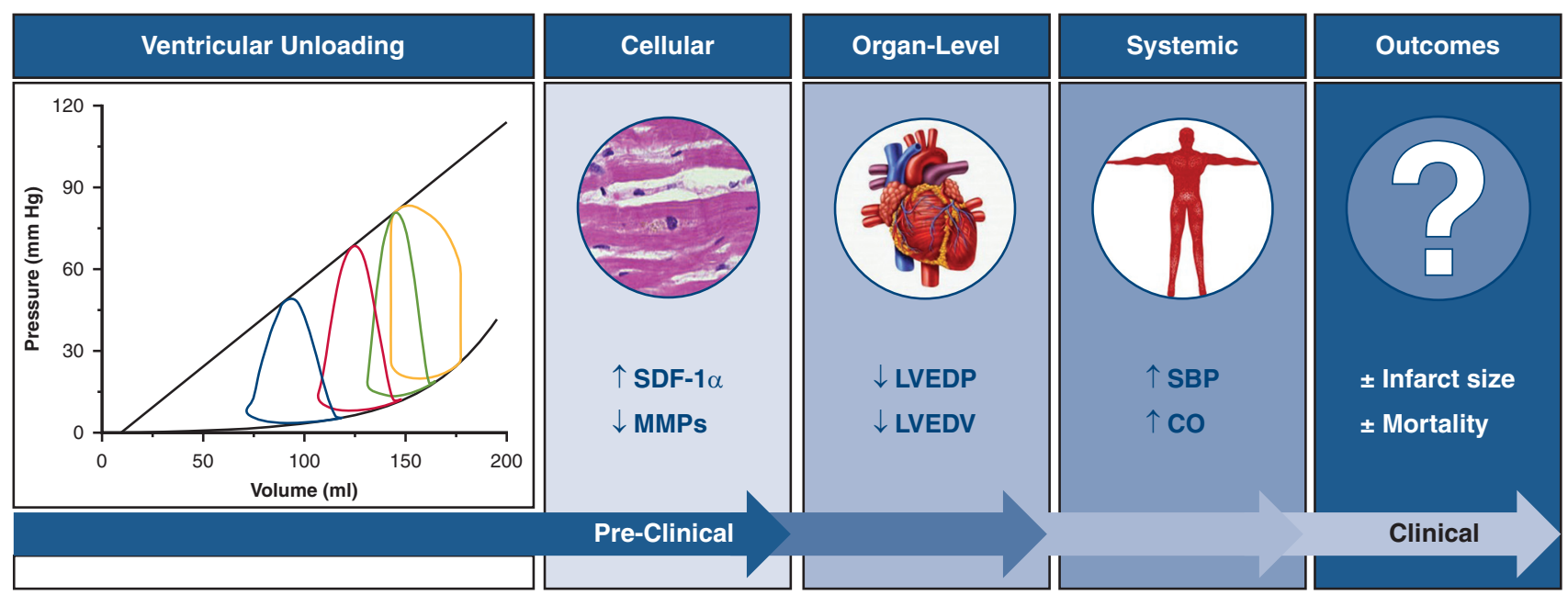

FIGURE 1. Cellular, organ, and systematic level benefits associated with left ventricular unloading. The favorable effects of LV unloading in preclinical models are wide-ranging but have yet to extend to clinical outcomes in patients with AMI. At the cellular level, LV unloading induces a cardioprotective program characterized by increased expression of SDF- $1 \alpha$ and a reduction in MMPs. At the organ level, as seen in the pressure-volume loops in the left-most box, unloading reduces LV end-diastolic pressure and volume. These benefits translate, at the systemic level, to increases in cardiac output and systolic blood pressure. Whether these benefits of unloading reduce infarct size, and ultimately, the incidence of heart failure and mortality after AMI remains to be seen. $S D F-1 \alpha$, Stromal-derived factor- $1 \alpha ; M M P$, matrix metalloproteinase; $L V E D P$, left ventricular end-diastolic pressure; $L V E D V$, left ventricular end-diastolic volume; $S B P$, systolic blood pressure; $C O$, cardiac output.

many survivors of AMI that contribute to phenomena like microvascular dysfunction, which can also impact infarct size and clinical outcomes.

This extensive background work set the stage for in vivo studies, prompting the groundbreaking Door-to-Unload in ST-segment elevation MI (DTU-STEMI) trial. ${ }^{5}$ Informed by preclinical work establishing the minimum time required to trigger the cardioprotective cascade of LV unloading, Kapur and colleagues ${ }^{5}$ designed a feasibility study randomizing patients to 30 minutes of unloading with an Impella device before reperfusion versus immediate unloading and reperfusion. Average infarct size trended lower (not statistically significantly) in patients with the 30 minutes of unloading before reperfusion. Thus, while this study was statistically neutral with respect to infarct size, it is critical to remember that it was not designed for this purpose. Rather, DTU-STEMI was intended to demonstrate the feasibility and safety of the DTU concept, and, indeed, there was no significant difference in the frequency of complications with delayed versus immediate reperfusion and that total door-to-balloon time remained less than 90 minutes in both groups.

Thus, it remains to be seen whether the benefits of unloading identified in preclinical settings can be replicated in the real world and usher in a new paradigm of care for patients with AMI (Figure 1). The recently initiated Primary Unloading and Delayed Reperfusion in STElevation Myocardial Infarction: The STEMI-DTU Trial (ClinicalTrials.gov Identifier: NCT03947619) is designed precisely to address this question. Our job, in the meantime, is to keep an open mind and, if possible, contribute to the speedy completion of this pivotal study.

\section{References}

1. Goodwin MS, Selzman CH. Take a load off: unloading and reperfusion. J Thorac Cardiovasc Surg. 2021;161:2046-50.

2. Esposito ML, Zhang Y, Qiao X, Reyelt L, Paruchuri V, Schnitzler GR, et al. Lef ventricular unloading before reperfusion promotes functional recovery after acute myocardial infarction. J Am Coll Cardiol. 2018;72:501-14.

3. Smalling RW, Cassidy DB, Barrett R, Lachterman B, Felli P, Amirian J. Improved regional myocardial blood flow, left ventricular unloading, and infarct salvage using an axial-flow, transvalvular left ventricular assist device. A comparison with intra-aortic balloon counterpulsation and reperfusion alone in a canine infarction model. Circulation. 1992;85:1152-9.

4. Meyns B, Stolinski J, Leunens V, Verbeken E, Flameng W. Left ventricular suppor by catheter-mounted axial flow pump reduces infarct size. J Am Coll Cardiol. 2003;41:1087-95.

5. Kapur NK, Alkhouli MA, DeMartini TJ, Faraz H, George ZH, Goodwin MJ et al. Unloading the left ventricle before reperfusion in patients with anterior ST-segment-elevation myocardial infarction. Circulation. 2019;139: $337-46$. 